\title{
Isolation and molecular characterization of fowl aviadenovirus associated with inclusion body hepatitis from poultry in Banten and West Java, Indonesia
}

\author{
Otto Sahat Martua Silaen ${ }^{1,2}$, Sri Murtini ${ }^{1}$, ${ }^{\text {, Joko Pamungkas }}{ }^{(\mathbb{D})}$ and Christian Marco Hadi Nugroho ${ }^{(\mathbb{D})}$
}

1. Department of Animal Infectious Disease and Veterinary Public Health, Faculty of Veterinary Medicine, IPB University, Bogor, Indonesia; 2. Animal Health Diagnostic Laboratory, PT Medika Satwa Laboratories, Bogor, Indonesia. Corresponding author: Sri Murtini, e-mail: smurtinifs@yahoo.com

Co-authors: OSMS: ottosiyl@gmail.com, JP: jpi-pssp@indo.net.id, CMHN: christianmarco3085@gmail.com Received: 06-05-2020, Accepted: 06-08-2020, Published online: 22-09-2020

doi: www.doi.org/10.14202/vetworld.2020.1940-1946 How to cite this article: Silaen OSM, Murtini S, Pamungkas J, Nugroho CMH (2020) Isolation and molecular characterization of fowl aviadenovirus associated with inclusion body hepatitis from poultry in Banten and West Java, Indonesia, Veterinary World, 13(9): 1940-1946.

\begin{abstract}
Background and Aim: Fowl avidenoviruses (FAdVs) are generally considered ubiquitous, but certain serotypes and strains are known to be associated with primary diseases, such as inclusion body hepatitis (IBH). Since 2018, the outbreak of IBH has been reported in part provinces of Indonesia. This study aimed to isolate and molecularly characterize the FAdV from Banten and West Java Provinces of Indonesia and described the phylogenetic relationship with the FAdV that has been characterized in other countries.

Materials and Methods: A total of 25 FAdV archive samples have been collected from January to August 2019 from clinical cases of FAdV infection in Banten and West Java Provinces, Indonesia. Collected samples were inoculated in 10-day-old specific-pathogenic-free chicken embryonated eggs. Hexon gene of FAdV was detected using polymerase chain reaction (PCR) with a primer set from previous study. To gain a better understanding of the FAdV genetic properties and construct the phylogeny tree, the PCR products were sequenced and subjected to a BLAST search and inferred using the neighbor-joining method by bootstrap test $1000 \times$.
\end{abstract}

Results: FAdV-D and FAdV-E are present in Banten, Indonesia. The phylogenetic analysis of 850 nucleotides that encode 289 amino acid of the partial hexon gene shows that the isolates Broiler/MSL/Ciputat-149/18, Broiler/MSL/Lebak-151/18, and Broiler/MSL/Ciputat-29/19 have 100\% homology with FAdV-E TR/BVKE/R/D-1 from Turkey, whereas the isolates Layer/MSL/Ciputat-20/19 and Broiler/MSL/Ciputat-30/19 have 100\% homology with FAdV-D strain 685 from Canada.

Conclusion: The present study provides updates of the circulating FAdV in commercial poultry flocks in Banten and West Java Provinces, Indonesia. Since the FAdV vaccine was unavailable in Indonesia, this result might be used as guidance to select a proper FAdV vaccine strain. Our result indicates that at least two FAdV species were circulating among poultry in Banten and West Java Provinces, Indonesia; they are FAdV-D and FAdV-E.

Keywords: fowl aviadenovirus, hexon gene, Indonesia, molecular characterization, poultry.

\section{Introduction}

Adenoviruses are members of the family Adenoviridae, non-enveloped with icosahedral nucleocapsids that contain a double-stranded DNA. They are divided into the following five genera: Atadenovirus, Aviadenovirus, Ichtadenovirus, Mastadenovirus, and Siadenovirus [1]. Many poultry species such as chickens, geese, ducks, turkeys, and pheasants can be infected by Aviadenovirus. Various diseases caused by aviadenovirus include egg drop syndrome, hemorrhagic enteritis, pheasant marble spleen disease, quail bronchitis, and inclusion body hepatitis (IBH) [2].

$\mathrm{IBH}$ is one of the diseases caused by the fowl avidenoviruses (FAdVs) infection, which acutely

Copyright: Silaen, et al. Open Access. This article is distributed under the terms of the Creative Commons Attribution 4.0 International License (http://creativecommons.org/licenses/by/4.0/), which permits unrestricted use, distribution, and reproduction in any medium, provided you give appropriate credit to the original author(s) and the source, provide a link to the Creative Commons license, and indicate if changes were made. The Creative Commons Public Domain Dedication waiver (http://creativecommons.org/ publicdomain/zero/1.0/) applies to the data made available in this article, unless otherwise stated. attacks young chickens between 1 and 5 weeks. The disease is characterized by an increase in chicken mortality which reaches its peak on the $4^{\text {th }}$ or $5^{\text {th }}$ day after infection. The main characteristic of this disease appears in an enlarged liver, bleeding, and necrosis. The presence of intranuclear basophilic inclusion bodies in hepatocyte cells was the main microscopic lesions [3]. The death rate caused by IBH varies usually below $10 \%$, but can be more than $30 \%$ [4]. Since the first case identified in the United States in 1963, IBH disease has become a serious threat to the poultry industry worldwide. In some countries such as Pakistan, India, Korea, Canada, the United States, Hungary, Japan, and China, IBH disease has caused considerable economic losses [5].

The transmission of FAdV can occur horizontally or vertically. Horizontal transmission occurs through feces, food, water, and virus-contaminated environments, whereas vertical transmission occurs through eggs from breeder chicken infected with FAdV-4 and FAdV-8 [6]. Infected chickens that shown no clinical symptoms are thought to be the source of the spread 
of IBH disease, especially to chickens with immune system disorders. The main species that cause IBH infection in chickens are FAdV-D and FAdV-E with serotypes 7, 8a, 8b, and 11 [7]. Over the past few years, there have been complaints of the presence of IBH or hepatitis hydropericardium syndrome in Indonesia. The outbreak of the syndrome started in 2018 [8].

This study aims to isolate and determine FAdV strain and genetic characterization of hexon gene of FAdV isolated from poultry in Banten and West Java Provinces, Indonesia. The results obtained are expected to provide updated information about the presence of the FAdV in this region, as well as providing molecular character data and genetic relationships with the FAdV in other countries so that it can be a reference for the selection of seed virus IBH vaccine.

\section{Materials and Methods}

\section{Ethical approval}

No live animals were used in the present study. Therefore, no ethical approval was necessary. This study was performed based on the regulations for Research in Animal Health of Indonesian Law on Livestock and Animal Health (UU/18/2009, article 80).

\section{Study period and location}

This research was conducted from March 2019 to January 2020 in the Virology Laboratory Research and Development Unit (R\&D) of PT Medika Satwa Laboratories, Bogor and in the Integrated Laboratory Department of Animal Infectious Disease and Veterinary Public Health, Faculty of Veterinary Medicine, IPB University, Bogor, Indonesia

\section{Samples}

A total of 25 samples were an archival collection of PT Medika Satwa Laboratories, West Java, Indonesia, that isolated from problematic flocks showing IBH such as clinical symptoms and decrease in production. The samples were collected from commercial poultry flocks in some districts of Banten and West Java Provinces: Bogor $(n=9)$, Ciamis $(n=2)$, Lebak $(n=3)$, Sukabumi $(n=3)$, Subang $(n=2)$, and Tanggerang $(n=6)$. The owner of each sample was given an informed consent and agreed that the sample was used in this study.

\section{Virus propagation}

Virus propagation was done by inoculated $0.2 \mathrm{ml}$ filtered suspension $(20 \% \mathrm{~W} / \mathrm{V})$ of pooled tissue samples from one farm to the allantoic cavity of three 10-day-old fertilized specific-pathogen-free (SPF) chicken eggs. The inoculum contains $200 \mu \mathrm{g} / \mathrm{ml}$ penicillin and $100 \mu \mathrm{g} / \mathrm{ml}$ streptomycin. The SPF chicken eggs that have been inoculated were incubated at $37^{\circ} \mathrm{C}$ and observed for a maximum 6 days [4]. The negative embryo control was three 10-day-old fertilized SPF chicken eggs inoculated by $0.2 \mathrm{~mL}$ sterile phosphate-buffered saline. The embryo was observed for any signs of abnormalities, such as bleeding and death. The allantoic fluid was harvested from the SPF chicken eggs that may be dead and live. Furthermore, allantoic fluid was pooled and processed for DNA extraction and polymerase chain reaction (PCR).

\section{DNA extraction and PCR}

The entire DNA allantoic fluid was extracted using Viral Nucleic Acid Extraction Kit II (Geneaid, Taiwan) according to the manufacturer's protocol. The DNAs were dissolved in $50 \mu \mathrm{L}$ nuclease-free water and directly used for subsequent PCR or stored at $-20^{\circ} \mathrm{C}$. The FAdV hexon gene fragment was amplified using a published hexon A and hexon B primer set list in Table-1 [9] with expected PCR product size that is $897 \mathrm{bp}$. PCR amplification reaction was carried out in $50 \mu \mathrm{L}$ containing $5 \mu \mathrm{L}$ DNA template, $25 \mu \mathrm{L}$ KAPA2G Fast ReadyMix (Sigma-Aldrich, USA), $5 \mu \mathrm{L}$ primer $(500 \mathrm{nM})$, and $15 \mu \mathrm{L}$ DEPC-H2O. An amplification reaction was carried out with thermal profile at a pre-denaturation condition of $95^{\circ} \mathrm{C}$ for $30 \mathrm{~s}$, followed by 25 cycles of annealing $56^{\circ} \mathrm{C}$ for $30 \mathrm{~s}$, extension $72^{\circ} \mathrm{C}$ for $60 \mathrm{sec}$, and concluded with an additional final extension $72^{\circ} \mathrm{C}$ for $5 \mathrm{~min}$. Amplified samples were analyzed by electrophoresis in $1.5 \%$ agarose gel and stained by ethidium bromide. A molecular weight marker with $100 \mathrm{bp}$ (Geneaid, Taiwan) was used as a standard size $[10,11]$.

\section{Sequencing and analysis}

About $40 \mu \mathrm{L}$ each of PCR product of amplified hexon gene were sent for sequencing (First Base, Malaysia) and sequenced from both directions using BigDye ${ }^{\circledR}$ Terminator version 3.1 Cycle Sequencing Kit (Thermo Fisher Scientific, USA) with forward hexon A and reverse hexon B primer. Sequence alignment was conducted using MEGA 7 [12]. All standard FAdV sequences were downloaded from GenBank and compared with the sample nucleotide sequence. The phylogeny tree was inferred using the neighbor-joining method and tested using the bootstrap test of 1000 replicates.

\section{Results}

The propagation results showed that 9 of the 25 samples in the present study caused pathological lesions in the kidney, liver, heart, and skeletal muscles of the chicken embryo, but no dead chicken embryo was found until $144 \mathrm{~h}$ post-inoculation. The observation of the chicken embryo showed imperfect growth

Table-1: Hexon gene fragments and primer sequences used for PCR identification.

\begin{tabular}{llccc}
\hline Gene & Primer sequence & Size (bp) & Annealing temperature & References \\
\hline Hexon & (F) 5'- CAARTTCAGRCAGACGGT -3' & 897 & $56^{\circ} \mathrm{C}$ & [9] \\
& (R) 5'- TAGTGATGMCGSGACATCAT -3' & & & \\
\hline
\end{tabular}


compared to the control embryo. Most pathologic lesions that were found are swelling/hemorrhage of the liver with a brownish-yellow color with foci necrotic and a soft consistency of the heart with hydropericardium. Enlarged or pale kidneys were also observed in some inoculated embryos. No lesions were found in the control embryo (Figure-1). The summary of origin, age of the affected chickens, pathologic lesions, and PCR result are presented in Table-2.

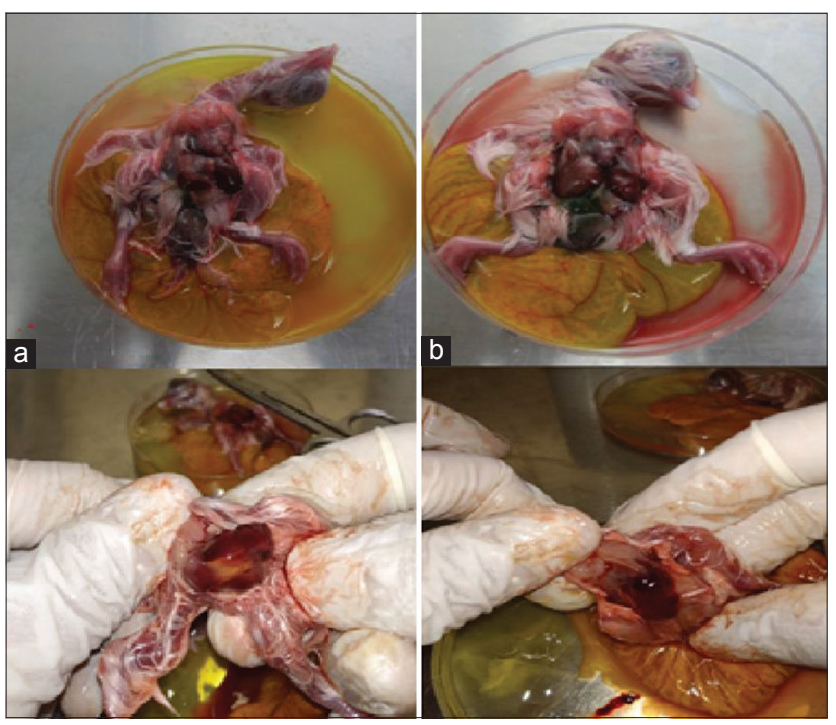

Figure-1: The pathologic lesions of the embryo, code a is the embryo inoculated by samples suspension, while code $b$ is a control embryo inoculated by sterile PBS.
PCR test results from the whole DNA of allantoic fluid SPF chicken eggs inoculated with field samples of suspected FAdV infection revealed amplifications of a hexon gene fragment as expected (897 bp) on 6 of 25 samples (Figure-2). The positive control was DNA from the first specific FAdV case obtained, while the negative control was non-template control (NTC). Six samples that showed positive results were three isolates from broiler farms in Ciputat, one isolate from layer farms in Ciputat, one isolate from layer farms in Sukabumi, and one isolate from broiler farms in Lebak. Of the six positive results, five have been sequenced and available in GenBank with accession numbers of MT104454-MT104458.

Hexon gene fragments result from five FAdV isolates obtained 850 nucleotides which encode about 289 amino acids. The homological analysis was performed by pairwise comparison which compares the nucleotide sequences of the hexon gene fragments from isolates in the present study with other FAdVs available at GenBank. The results of the phylogenetic analysis of the hexon gene fragments from FAdVs in the present study and other FAdVs available at GenBank database are presented in Figure-3. The result shows that three isolates classified into the same group, namely, Broiler/ MSL/Ciputat-149/18, Broiler/MSL/Lebak-151/18, and Broiler/MSL/Ciputat-29/19. The three isolates clustered to FAdV-E have 100\% homology with TR/ BVKE/R/D-1 (Accession No. MK937075) and 97\%

Table-2: List of origin, age of affected chickens, embryo pathologic lesions, and PCR result.

\begin{tabular}{|c|c|c|c|c|c|c|}
\hline No. & Samples code & Province & $\begin{array}{c}\text { Chicken age } \\
\text { (days) }\end{array}$ & $\begin{array}{l}\text { Embryo } \\
\text { mortality }\end{array}$ & Embryo pathologic lesion & PCR result \\
\hline 1 & Broiler/MSL/Ciputat-21/19 & Banten & 21 & Live & Normal & Negative \\
\hline 2 & Broiler/MSL/Ciputat-29/19 & Banten & 30 & Live & $\begin{array}{l}\text { Yellowish and hemorrhagic } \\
\text { liver }\end{array}$ & Positive \\
\hline 3 & Broiler/MSL/Ciputat-30/19 & Banten & 35 & Live & $\begin{array}{l}\text { Hepatomegaly and } \\
\text { hemorrhage }\end{array}$ & Positive \\
\hline 4 & Broiler/MSL/Ciputat-166/19 & Banten & 30 & Live & Normal & Negative \\
\hline 5 & Broiler/MSL/Ciputat-149/18 & Banten & 25 & Live & $\begin{array}{l}\text { Kidney swelling, } \\
\text { hemorrhagic liver }\end{array}$ & Positive \\
\hline 6 & Broiler/MSL/Lebak-151/18 & Banten & 17 & Live & Petechiae in skeletal muscle & Positive \\
\hline 7 & Broiler/MSL/Lebak-322/19 & Banten & 26 & Live & Normal & Negative \\
\hline 8 & Broiler/MSL/Sukabumi-165/19 & West Java & 39 & Live & Normal & Negative \\
\hline 9 & Broiler/MSL/Ciamis-240/19 & West Java & 25 & Live & Normal & Negative \\
\hline 10 & Broiler/MSL/Bogor-127-19 & West Java & 29 & Live & Pale hepatomegaly & Negative \\
\hline 11 & Broiler/MSL/Bogor-318/19 & West Java & 26 & Live & Yellowish liver & Negative \\
\hline 12 & Broiler/MSL/Bogor-378/19 & West Java & 26 & Live & Normal & Negative \\
\hline 13 & Broiler/MSL/Subang-324-19 & West Java & 17 & Live & Normal & Negative \\
\hline 14 & Broiler/Bogor-IP1/19 & West Java & 31 & Live & Normal & Negative \\
\hline 15 & Broiler/Bogor-IP2/19 & West Java & 31 & Live & Normal & Negative \\
\hline 16 & Broiler/Bogor-IP3/19 & West Java & 31 & Live & Normal & Negative \\
\hline 17 & Broiler/Bogor-IP4/19 & West Java & 31 & Live & $\begin{array}{l}\text { The liver is brittle and looks } \\
\text { yellow }\end{array}$ & Negative \\
\hline 18 & Broiler/Bogor-IP5/19 & West Java & 31 & Live & Normal & Negative \\
\hline 19 & Layer/MSL/Ciputat-20/19 & Banten & 175 & Live & Yellowish liver & Positive \\
\hline 20 & Layer/MSL/Lebak-450/19 & Banten & 210 & Live & Normal & Negative \\
\hline 21 & Layer/MSL/Sukabumi-83/19 & West Java & 217 & Live & $\begin{array}{l}\text { Kidney swelling, } \\
\text { hemorrhage in the liver }\end{array}$ & Positive \\
\hline 22 & Layer/MSL/Sukabumi-164/19 & West Java & 203 & Live & Normal & Negative \\
\hline 23 & Breeder/MSL/Ciamis-255/19 & West Java & 231 & Live & Normal & Negative \\
\hline 24 & Breeder/MSL/Ciputat-193/19 & Banten & 245 & Live & Normal & Negative \\
\hline 25 & Breeder/MSL/Subang-333-19 & West Java & 231 & Live & Normal & Negative \\
\hline
\end{tabular}




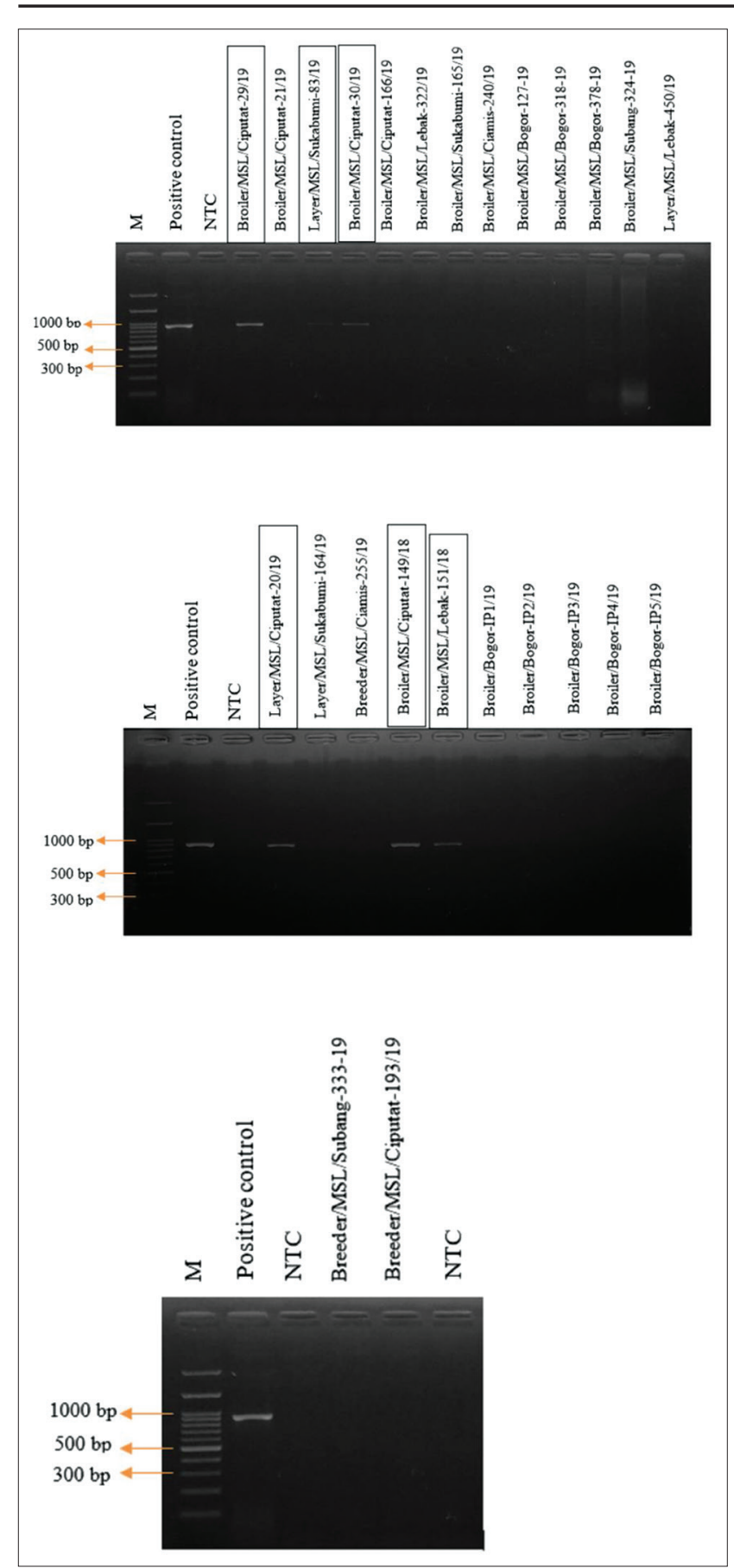

Figure-2: Amplification of hexon gene fragments determinants on agarose gel approximate 897 bp. M: 100 bp DNA ladder. NTC: Non-template control. The positive isolates from the samples we collected marked with rectangle shape in isolates name.

homology with Strain 764 which is FAdV-8b (Accession No. AF508958). The other two isolates Layer/MSL/ Ciputat-20/19 and Broiler/MSL/Ciputat-30/19 classified into FAdV-D have 100\% homology with strain 685 (Accession No. AF508947) and 95.7\% homology with P7-A FAdV-2 (Accession No. AF339915). The summary of homological analysis is presented in Table-3.

\section{Discussion}

The present study confirmed the presence of FAdVs in Banten and West Java Provinces, Indonesia.
We made confirmation after inoculation of the liver sample suspension from suspect field cases into fertilized 10-day-old SPF chicken eggs, PCR test, and sequencing of specific FAdV hexon gene fragments. The pathological characteristics of some embryos inoculated with the suspension of liver samples have the same lesions according to the statement of Dutta et al. [13], who said that a chicken liver suffering from IBH will look pale to yellowish, swollen, brittle, and have necrotic. Viral propagation in the present study was carried out to reproduce and isolate the virus from the chicken's liver suspect with IBH and fulfill the second Koch's postulate rule where the microorganism can be isolated into pure cultures [14].

FAdV infection has been reported in various countries, most cases of FAdV attack broiler chickens aged between 2 and 5 weeks [7,8,15-17]; however, FAdV infections in layers and breeders are not uncommon $[3,18]$. The results of this study did not distinguish observations and final confirmation between types of broiler, layer, or breeder farms.

We confirmed the presence of FAdV in 6 of 25 samples by PCR that showed positive results. Some samples, namely, Broiler/MSL/Bogor-127-19, Broiler/ MSL/Bogor-318/19, and Broiler/Bogor-IP4/19, caused pathological lesions in the embryo, but showed negative results by the PCR test. The other infections that showed pathologic lesions in the liver and kidneys like FAdVs infection are due to the presence of aflatoxin in the sample being tested. Aflatoxin is the most common factor associated with IBH because the clinical sign and immunosuppression effect are similar to FAdV infection [19].

The primer set used in the present study can amplify DNA from the five of FAdVs species. Negative results from the samples are strongly suspected due to the absence of specific FAdV or insufficient amount of DNA template so that it is below the detection limit [15]. To increase the amount of DNA virus (titer), it should be able to do the reinoculation twice into new SPF eggs before being discarded as negative [20]. Detection results with PCR continued to sequencing. Of the six positive isolates, there was one isolate that could not be sequenced (Layer/ MSL/Sukabumi-83/19). There are several reasons that sequencing cannot be done, one of them is inadequate concentration of the template, which can be seen through the band on the agarose gel. To increase the template concentration, it is generally possible to do a viral passage before molecular testing.

Data from the results of the present study have not been able to determine the source of spread nor the origin of FAdV infections in Indonesia. Wibowo et al. [8] reported that the highest number of FAdV cases in Indonesia between 2018 and 2019 came from East Kalimantan, East Java, and South Kalimantan, where the species that were infected are the same as FAdV found in the present study with homology 98.9-100\%. From these results, we conclude that the 


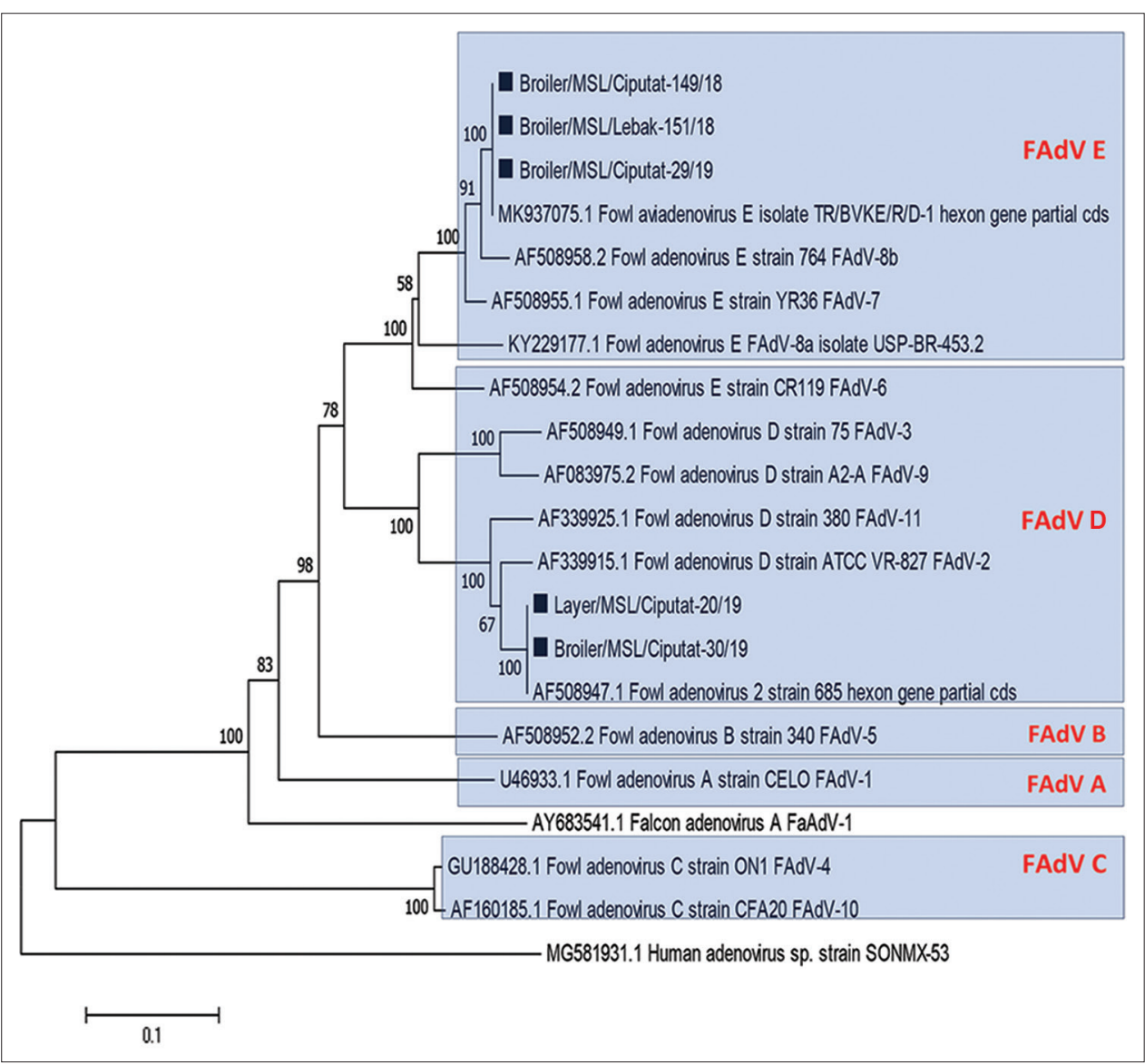

Figure-3: Phylogenetic tree of FAdV isolated from positive samples in Banten. Five isolates in the present study were marked with while other isolates were available at GenBank with the accession number attached. The phylogenetic tree was constructed using the neighbor-joining method with 1000 bootstraps replicating on Mega 7 [22]. Sequence of a human adenovirus sp. SONMX-53 accession number MG581931 is coanalyzed as an out group.

Table-3: List of homological analysis.

\begin{tabular}{|c|c|c|c|c|c|c|}
\hline \multirow[t]{2}{*}{ Virus species } & \multirow[t]{2}{*}{ Isolate/strain } & \multicolumn{5}{|c|}{ Homology } \\
\hline & & 1 & 2 & 3 & 4 & 5 \\
\hline FAdV A & Falcon adenovirus $\mathrm{A}$ & 59.7 & 59.7 & 59.2 & 59.7 & 59.2 \\
\hline FAdV A & CELO FAdV-1 & 67.4 & 67.4 & 64.2 & 67.4 & 64.2 \\
\hline FAdV B & Strain 340 FAdV-5 & 73.6 & 73.6 & 70.2 & 73.6 & 70.2 \\
\hline FAdV C & ON1 FAdV-4 & 38.5 & 38.5 & 37.1 & 38.5 & 37.1 \\
\hline FAdV C & CFA20 FAdV-10 & 38 & 38 & 36.9 & 38 & 36.9 \\
\hline FAdV D & ATCC VR-827 FAdV-2 & 75.4 & 75.4 & 95.7 & 75.4 & 95.7 \\
\hline FAdV D & Strain 75 FAdV-3 & 73.8 & 73.8 & 80.4 & 73.8 & 80.4 \\
\hline FAdV D & A2-A FAdV-9 & 73.8 & 73.8 & 82.2 & 73.8 & 82.2 \\
\hline FAdV D & Strain 380 FAdV-11 & 74.7 & 74.7 & 93.2 & 74.7 & 93.2 \\
\hline FAdV D & Strain 685 & 76.1 & 76.1 & 100 & 76.1 & 100 \\
\hline FAdV E & CR119 FAdV-6 & 88.4 & 88.4 & 75.6 & 88.4 & 75.6 \\
\hline FAdV E & YR36 FAdV-7 & 96.6 & 96.6 & 75.2 & 96.6 & 75.2 \\
\hline FAdV E & USP-BR-453.2 FAdV-8a & 87.9 & 87.9 & 73.8 & 87.9 & 73.8 \\
\hline FAdV E & 764 FAdV-8b & 97 & 97 & 75.2 & 97 & 75.2 \\
\hline FAdV E & TR/BVKE/R/D-1 & 100 & 100 & 76.1 & 100 & 76.1 \\
\hline HAdV & SONMX-53 & 25.3 & 25.3 & 25.1 & 25.3 & 25.1 \\
\hline FAdV E & Broiler/MSL/Ciputat-149/18 & / & 100 & 76.1 & 100 & 76.1 \\
\hline FAdV E & Broiler/MSL/Lebak-151/18 & 100 & / & 76.1 & 100 & 76.1 \\
\hline FAdV D & Layer/MSL/Ciputat-20/19 (3) & 76.1 & 76.1 & / & 76.1 & 100 \\
\hline FAdV E & Broiler/MSL/Ciputat-29/19 (4) & 100 & 100 & 76.1 & / & 76.1 \\
\hline FAdV D & Broiler/MSL/Ciputat-30/19 (5) & 76.1 & 76.1 & 100 & 76.1 & / \\
\hline
\end{tabular}

FAdVs associated with IBH in several provinces in Indonesia are the same strain.

The investigation by Wibowo et al. shows that the spread of FAdV occurs without a clear epizootiological relation [8]. Similar reports regarding the source of the FAdV spread also described in Japan by Mase and Nakamura [21]. FAdVs are known to be transmitted horizontally between flocks through 
the fecal-oral route and vertically in breeder chickens [16], but in the present study, we did not find any breeder farms infected with FAdV. Breeder farms that supply a 1-day-old chicken to some broiler farms in Ciputat may be the source of infection, but this needs further investigation.

Some hypotheses related to the cause of entry FAdV include migration of wild birds. However, there was only one report related to wild birds as a reservoir in the spread of FAdV available in PubMed [22] to prove this hypothesis. Research on the existence of FAdV in wild birds in Indonesia is needed. Some outbreak reports of FAdV in various countries include: Iran reported as a result of infection with FAdV-C and FAdV-E [23]; Japan caused by FAdV-A and FAdV-D [21]; Canada by FAdV-D and FAdV-E [7]; and India by FAdV-B, -C, -D, and -E [15].

In the Southeast Asia region, FAdV-D has been reported in Thailand [24], while FAdV-E has been reported in Malaysia [25]. Considering the close geographical distance, FAdV-D and FAdV-E detected in Indonesia may come from neighboring countries. Further phylogeography studies need to be done to estimate the origin of the FAdV circulating in Indonesia.

\section{Conclusion}

FAdV associated with IBH was successfully isolated from several chicken farms in Banten and West Java Provinces, Indonesia. Phylogenetic analysis revealed two FAdV species circulating in the Banten and West Java regions, which are FAdV-D and FAdV-E that belonged to serotypes 2 and $8 \mathrm{~b}$. The FAdV in this study was genetically identical to the previously isolated FAdV from Indonesia and the FAdV from Turkey and Canada.

\section{Authors' Contributions}

OSMS designed the study and drafted the manuscript under the supervision of SM and JP. CMHN collected samples and compiled the resource materials. OSMS and CHMN performed the test and data analysis under the supervision of SM and JP. All authors read and approved the final manuscript.

\section{Acknowledgments}

The authors would like to acknowledge the help of Dr. Sudarisman M.S, drh. Lily Natalia M.S, and drh. Adin Priadi from PT Medika Satwa Laboratories, West Java, Indonesia, for Microbiology Laboratory facilities. The authors would like to thank drh. Ryan Septa Kurnia, Firmansyah S.Si, and M. Fardiz as technical assistance for supporting this study. This study was funded by PT Medika Satwa Laboratories, West Java, Indonesia, but we have not used any commercial product of PT Medika Satwa Laboratories for this study.

\section{Competing Interests}

The authors declare that they have no competing interests.

\section{Publisher's Note}

Veterinary World remains neutral with regard to jurisdictional claims in published institutional affiliation.

\section{References}

1. Adams, M.J., Lefkowitz, E.J., King, A.M., Harrach, B., Harrison, R.L., Knowles, N.J., Kropinski, A.M., Krupovic, M., Kuhn, J.H., Mushegian, A.R., Nibert, M.L., Sabanadzovic, S., Sanfaçon, H., Siddell, S.G., Simmonds, P., Varsani, A., Zerbini, F.M., Orton, R.J., Smith, D.B., Gorbalenya, A.E. and Davison, A.J. (2017) 50 years of the international committee on taxonomy of viruses: Progress and prospects. Arch. Virol., 162(5): 1441-1446.

2. Domanska, B.K., Tomczyk, G., Smietanka, K., Kozaczynski, W. and Minta, Z. (2011) Molecular characterization of fowl adenoviruses isolated from chickens with gizzard erosions. Poult. Sci., 90(5): 983-989.

3. Choi, K.S., Kye, S.J., Kim, J.Y., Jeon, W.J., Lee, E.K., Park, K.Y. and Sung, H.W. (2012) Epidemiological investigation of outbreaks of fowl adenovirus infection in commercial chickens in Korea. Poult. Sci., 91(10): 2502-2506.

4. Gulhane, A.B., Gogoi, S.M., Deshpande, A.A. and Balaguru, P. (2016) Isolation and characterization of different fowl adenovirus types associated with inclusion body hepatitis in broiler chickens of India. J. Pure Appl. Microbiol., 10(1): 417-423.

5. Wajid, A., Basharat, A., Shahid, M.A., Muntaha, S.T., Basit, A., Hussain, T., Tahir, M.F., Azhar, M., Babar, M.E. and Rehmani, S.F. (2018) Molecular characterization and phylogenetic analysis of fowl adenoviruses isolated from commercial poultry flocks in Pakistan during 2014-15. Pak. J. Zool., 18(5): 50.

6. Li, P.H., Zheng, P.P., Zhang, T.F., Wen, G.Y., Shao, H.B. and Luo, Q.P. (2017) Fowl adenovirus serotype 4: Epidemiology, pathogenesis, diagnostic detection, and vaccine strategies. Poult. Sci., 96(8): 2630-2640.

7. Ojkic, D., Krell, P.J., Tuboly, T. and Nagy, E. (2008) Characterization of fowl adenoviruses isolated in Ontario and Quebec, Canada. Can. J. Vet. Res., 72(3): 236-241.

8. Wibowo, M.H., Sahesty, A., Mahardika, B.K., Purwanto, B., Lestariningsih, C.L. and Suardana, I.B.K. (2019) Epizootiology, clinical signs, and phylogenetic analysis of fowl adenovirus in chicken farms in Indonesia from 2018 to 2019. Avian Dis., 63(4): 619-624.

9. Meulemans, G., Boschmans, M., Berg, T.P. and Decaesstecker, M. (2001) Polymerase chain reaction combined with restriction enzyme analysis for detection and differentiation of fowl adenoviruses. Avian Pathol., 30(6): 655-660.

10. Kurnia, R.S., Indrawati, A., Mayasari, N. and Priadi, A. (2018) Molecular detection of genes encoding resistance to tetracycline and determination of plasmid-mediated resistance to quinolones in avian pathogenic Escherichia coli in Sukabumi, Indonesia. Vet. World, 11(11): 1581-1586.

11. Setiawaty, R., Soejoedono, R.D. and Poetri, O.N. (2019) Genetic characterization of $\mathrm{S} 1$ gene of infectious bronchitis virus isolated from commercial poultry flocks in West Java, Indonesia. Vet. World, 12(2): 231-235.

12. Kumar, S., Stecher, G. and Tamura, K. (2016) MEGA7: Molecular evolutionary genetics analysis version 7.0 for bigger datasets. Mol. Biol. Evol., 33(7): 1870-1874.

13. Dutta, B., Gogoi, S.M., Sarmah, M., Bora, M.K. and Pathak, D.C. (2017) Pathology of inclusion body hepatitis hydropericardium syndrome (IBH-HPS) in broiler chicken. Int. J. Chem. Stud., 5(3): 458-461.

14. Nagafuchi, S., Mine, K., Takahashi, H., Anzai, K. and Yoshikai, Y. (2019) Viruses with masked pathogenicity and genetically susceptible hosts-how to discover potentially pathogenic viruses. J. Med. Virol., 91(8): 1365-1367. 
15. Mittal, D., Jindal, N., Tiwari, A.K. and Khokhar, R.S. (2014) Characterization of fowl adenoviruses associated with hydropericardium syndrome and inclusion body hepatitis in broiler chickens. Virusdisease, 25(1): 114-119.

16. Zhao, J., Zhong, Q., Zhao, Y., Hu, Y.X. and Zhang, G.Z. (2015) Pathogenicity and complete genome characterization of fowl adenoviruses isolated from chickens associated with inclusion body hepatitis and hydropericardium syndrome in China. PLoS One, 10(7): $\mathrm{e} 0133073$.

17. Nateghi, E., Razmyar, J. and Bassami, M.R. (2013) Molecular characterization of avian adenoviruses in Iranian broiler flocks. Iran. J. Vet. Res., 15(2): 164-167.

18. Radwan, M.M., El-Deeb, A.H., Mousa, M.R., El-Sanousi, A.A. and Shalaby, M.A. (2019) First report of fowl adenovirus 8a from commercial broiler chickens in Egypt: Molecular characterization and pathogenicity. Poult. Sci., 98(1): 97-104.

19. Naseem, M.N., Saleemi, M.K., Khan, A., Khatoon, A., Gul, S.T., Rizvi, F., Ahmad, I. and Fayyaz, A. (2018) Pathological effects of concurrent administration of aflatoxin B1 and fowl adenovirus-4 in broiler chicks. Microb. Pathog., 121: 147-154.

20. Stanley, A.P., Walter, A.O., Paul, A.O. and Kathryn, M.E. (2012) Vaccines. $7^{\text {th }}$ ed. Elsevier, Amsterdam. p466-468.
21. Mase, M. and Nakamura, K. (2014) Phylogenetic analysis of fowl adenoviruses isolated from chickens with gizzard erosion in Japan. J. Vet. Med. Sci., 76(11): 1535-1538.

22. Kumar, R., Kumar, V., Asthana, M., Shukla, S.K. and Chandra R. (2010) Isolation and identification of a fowl adenovirus from wild Black Kites (Milvus migrans). J. Wildl. Dis., 46(1): 272-276.

23. Yasmeen, S., Siddique, N., Athar-Abbas, M., Ali, A., Rafique, S., Rashid, F., Shah, A.U., Mehmood, F., Begum, I., Javaid, T., Jaffery, S.M.H., Ali, R. and Naeem, K. (2017) Fiber gene based molecular and biological characterization of hydropericardium-hepatitis syndrome associated avian adenoviruses. Iran. J. Vet. Res., 18(3): 190-196.

24. Junnu, S., Lertwatcharasarakul, P., Jala, S., Phattanakunanan, S., Moonjit, P. and Songserm, T. (2014) Developing an indirect ELISA based on recombinant hexon protein for serological detection of inclusion body hepatitis in chickens. J. Vet. Med. Sci., 76(2): 289-293.

25. Sohaimi, N.M., Bejo, M.H., Omar, A.R., Ideris, A. and Isa, N.M. (2018) Hexon and fiber gene changes in an attenuated fowl adenovirus isolate from Malaysia in embryonated chicken eggs and its infectivity in chickens. J. Vet. Sci., 19(6): 759-770.

\section{$* * * * * * * *$}

